\title{
DESAIN DAN IMPLEMENTASI REAL-TIME VISIBLE LIGHT COMMUNICATION SYSTEMS BERBASIS BPSK
}

\author{
Trio Adiono ${ }^{1}$, Angga Pradana $^{2}$, Syifaul Fuada ${ }^{3}, \&$ Yulian Aska ${ }^{4}$ \\ ${ }^{1}$ Sekolah Teknik Elektro dan Informatika, Institut Teknologi Bandung; \\ ${ }^{2,3,4}$ University Center of Excellence on Microelectronics, Institut Teknologi Bandung \\ E-mail: tadiono@stei.itb.ac.id
}

\begin{abstract}
In previous studies, the author has successfully designed a low-cost VLC system with digital modulation, i.e., signel pulse width modulation (1-PWM) with bit-rate of $3.3 \mathrm{kbps}$ and 2-PWM (6.2 kbps). This research motivation is to increase the data rate of the VLC system by OFDM. The Binary shift-keying modulation (BPSK) modulation was selected as a Mapper (Demodulator). As for the VLC system hardware, the authors utilize previous research. Hence, this research is limited to proof-of-concept (POC) to verify that BPSK modulation is faster than 1-PWM and 2-PWM. The test results show that BPSK modulation has twice transfer rate speed compared to 2-PWM, which is 13.4 kbps. Other tests performed are Bit-Error-Rate (BER) measurement with variations in optical channel distance and reception angle.
\end{abstract}

Keywords: BPSK, OFDM, Visible light communication

\begin{abstract}
ABSTRAK
Pada penelitian sebelumnya, penulis telah berhasil mendesain sistem low-cost visible light communication (VLC) dengan modulasi digital single pulse width modulation (1-PWM) dengan bitrate 3,3 kbps dan 2-PWM (6,2 kbps). Motivasi dari penelitian ini adalah menigkatkan laju data dengan menggunakan OFDM. Modulasi binary shift-keying modulation (BPSK) dipilih sebagai Mapper. Adapun hardware sistem VLC, penulis memanfaatkan penelitian yang sebelumnya sehingga penelitian ini sebatas proof-of-concept (POC) untuk membuktikan bahwa modulasi BPSK lebih cepat daripada 1-PWM dan 2-PWM. Hasil pengujian menunjukkan bahwa modulasi BPSK memiliki kecepatan dua kali lipat dibandingkan 2-PWM, yakni 13.4 kbps. Pengujian lain yang dilakukan adalah pengukuran Bit-error-rate (BER) dengan variasi jarak kanal optik dan sudut penerimaan.
\end{abstract}

Kata Kunci: BPSK, Komunikasi cahaya tampak, OFDM

\section{PENDAHULUAN}

VLC merupakan salah satu alternatif komunikasi nirkabel yang menggunakan cahaya tampak dengan panjang gelombang $380 \mathrm{~nm}$ s.d. $780 \mathrm{~nm}$ sebagai medium komunikasi [1]. Dalam beberapa tahun terakhir, topik VLC telah menarik perhatian banyak peneliti di seluruh dunia seiring dengan perkembangan teknologi LED [2]. Kemutakhiran teknologi LED memungkinkan alat penerangan ini memiliki efisiensi energi yang lebih baik, memiliki lifespan lebih lama dibandingkan alat penerangan konvensional (lampu pijar/neon) [3] dan juga lebih murah dari sisi harga. Selain itu, LED juga dapat dikendalikan dengan kecepatan tinggi hingga $10 \mathrm{MHz}$ sehingga memungkinkan untuk dapat dimanfaatkan sebagai antenna pada komunikasi jarak terbatas, yakni VLC. Dengan keterbatasan cakupan area LED, maka VLC disinyalir lebih aman (secure) dari penyadap dibandingkan komunikasi radio. Selain itu, VLC menjamin lebih aman dari gangguan elektromagnetik dan resiko kanker [4].

Sistem VLC dapat diplikasikan pada lingkungan dalam ruang, seperti perkantoran, rumah hunian, area bebas electromagnetic interference (EMI) seperti rumah sakit, ataupun area-area yang diharuskan untuk mampu menyediakan banyak koneksi bagi sejumlah besar pengguna serta perangkat secara simultan seperti convention center \& tempat publik. Pada penelitian sebelumnya, penulis telah berhasil mewujudkan sistem VLC berbasis modulasi digital 1-PWM untuk aplikasi indoor yang mampu menyediakan interkoneksi pointto-point dan berhasil mendemonstrasikan 
streaming teks dengan kecepatan maksimum 3,3 kbps [5].

Penulis meninjau bahwa keterbatasan kecepatan transfer data disebabkan oleh dua hal, yakni faktor penggunaan modulasi dan pemilihan komponen-komponen untuk hardware sistem VLC. Penelitian lanjutan telah berhasil membuktikan bahwa peningkatan modulasi (menggunakan 2-PWM) dapat mempercepat laju data (data rate) sebesar dua kali lipat, yakni 6,2 kbps [6]. Variasi PWM seperti 3-PWM atau 4-PWM sebagai pembawa data tidak mudah dilakukan, sehingga upaya lain untuk meningkatkan laju data adalah memanfaatkan modulasi multi-carrier.

Salah satu teknik multiplexing yang saat ini populer digunakan untuk aplikasi akses komunikasi cepat berbasis cahaya tampak adalah Orthogonal Frequency Division Multiplexing (OFDM). Meskipun lebih kompleks dibandingkan modulasi berbasis Pulse Time Modulation (PTM) seperti PWM dan PPM, teknik OFDM disinyalir dapat lebih menghemat bandwidth komunikasi karena membagi bandwidth lebar menjadi spektrum yang sempit (sub-carrier) dan saling overlap. Sebagai akibat, transfer data akan lebih cepat dibandingkan PTM.

OFDM adalah skema transmisi data yang mampu menghasilkan transfer data kecepatan tinggi dengan memanfaatkan sub-carrier yang saling orthogonal. OFDM merupakan metode encoding data digital pada frekuensi multicarrier. OFDM telah lama diterapkan pada teknologi komunikasi nirkabel berbasis radio seperti Wireless Fidelity (Wi-Fi) dan 4G Long Term Evolution (LTE). Umumnya, output dari modulator OFDM adalah bilangan kompleks sehingga ketika diterapkan pada sistem VLC, modulasi quadrature (yakni BPSK, QPSK, QAM-16, QAM-32) tidaklah memungkinkan. VLC menggunakan teknik intensity modulation direct detection (IM/DD), maka informasi fasa negatif tidak dapat ditransmisikan oleh LED yang mengakibatkan sinyal yang diterima oleh photodiode ada yang terpotong. Dengan demikian, sistem OFDM yang banyak digunakan pada sistem komunikasi radio harus dimodifikasi.

Phase shift keying (PSK) adalah skema mapper-demapper pada sistem OFDM. Prinsip kerja pada bagian mapper OFDM adalah melewatkan data dengan mengubah-ubah fase dari sinyal referensi (sinyal pembawa). PSK menggunakan fase sejumlah bilangan terhingga, masing-masing menempatkan pola unik dari dijit biner. Biasanya, masing-masing fase mengkodekan sejumlah bit. Masing-masing pola bit-bit membentuk simbol yang direpresentasikan dengan fase tertentu. Sedangkan pada sisi demapper didesain untuk dapat menentukan fase sinyal yang diterima dan memetakan balik ke bentuk simbol yang asli, sehingga data asli dapat diperoleh kembali [7].

Binary Phase Shift Keying (BPSK) adalah bentuk paling sederhana dari PSK yang menggunakan dua fasa yang terpisah sejauh $180^{\circ}$. Lokasi titik dalam diagram konstelasi bebas dengan syarat kedua titik terpisah sejauh $180^{\circ}$. Ilustrasi mapper BPSK ditunjukkan pada Gambar 1 dimana titik-titik tersebut terletak pada sumbu real, pada $0^{\circ}$ dan $180^{\circ}$. Pada modulasi BPSK, sinyal direpresentasikan dalam dua kemungkinan. Sinyal 1 direpresentasikan dengan memberikan pergeseran fasa sinyal carrier sebesar $0^{\circ}$. Sedangkan sinyal 0 direpresentasikan dengan menggeser fasa sinyal carrier sebesar $180^{\circ}$ [8].

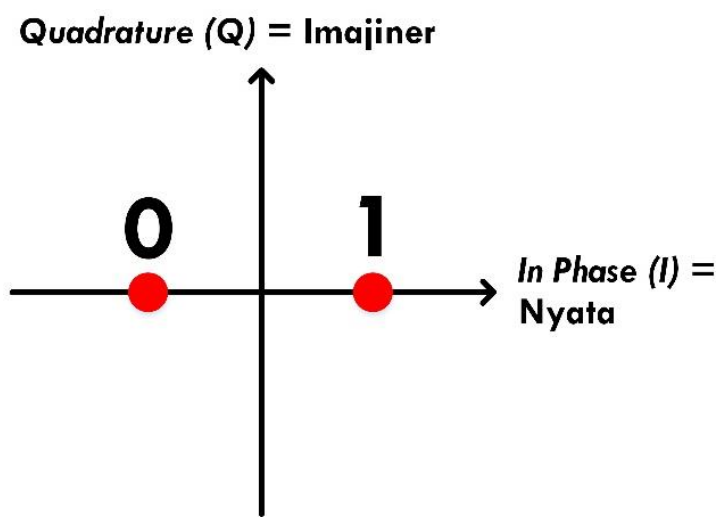

Gambar 1. Diagram konstelasi untuk modulasi BPSK gray-coded, direproduksi dari [8]

Astharini, dkk mendesain beberapa modulasi PSK (salah satunya adalah BPSK) untuk sistem optik [9], namun hanya terbatas pada simulasi Matlab sehingga tidak real-time. Simulasi BPSK juga dilakukan oleh Malik, dkk [10] dan Sonmez \& Akbal [11] pada Field Programmable-Gate Array (FPGA) untuk aplikasi generik. Selanjutnya Suresh, dkk merealisasikan hardware untuk membangkitkan sinyal BPSK [12], namun sisi aplikasinya tidak didiskusikan. Sementara pada penelitian ini, penulis mendesain modulasi BPSK sampai tahap proof-of-concept pada sistem point-topoint VLC. Disamping itu, sistem VLC 
didesain agar mampu diakses secara real-time sehingga data yang dikirim oleh transmitter akan ditampilkan oleh receiver.

Kekurangan dari modulasi BPSK adalah hanya mampu memodulasikan 1 bit per simbol. Sehingga jika dibandingkan mapper yang lain seperti QPSK dan QAM, laju data BPSK lebih rendah namun memiliki potensi nilai BER yang lebih kecil. Karena tujuan penelitian adalah sebagai Proof-of-concept modulasi BPSK pada sistem VLC, maka pada penelitian ini penulis memanfaatkan hardware rangkaian AFE transceiver dari [13]. Adapun bandwidth rangkaian AFE adalah maksimum $50 \mathrm{kHz}$. Maka dari itu, hipotesis dari penelitian ini adalah laju data dari sistem VLC berbasis
OFDM dengan mapper BPSK tetap lebih cepat dari modulasi 1-PWM dan 2-PWM namun tidak signifikan.

\section{METODE}

Penelitian diawali mendesain blok diagram sistem OFDM (Gambar 2) yang terdiri atas blok transmitter dan blok receiver. Bagian blok yang berada di dalam kotak garis putusputus diimplementasikan pada modul mikrokontroler STM32F4. Sistem VLC dalam penelitian ini adalah satu arah (Downlink).
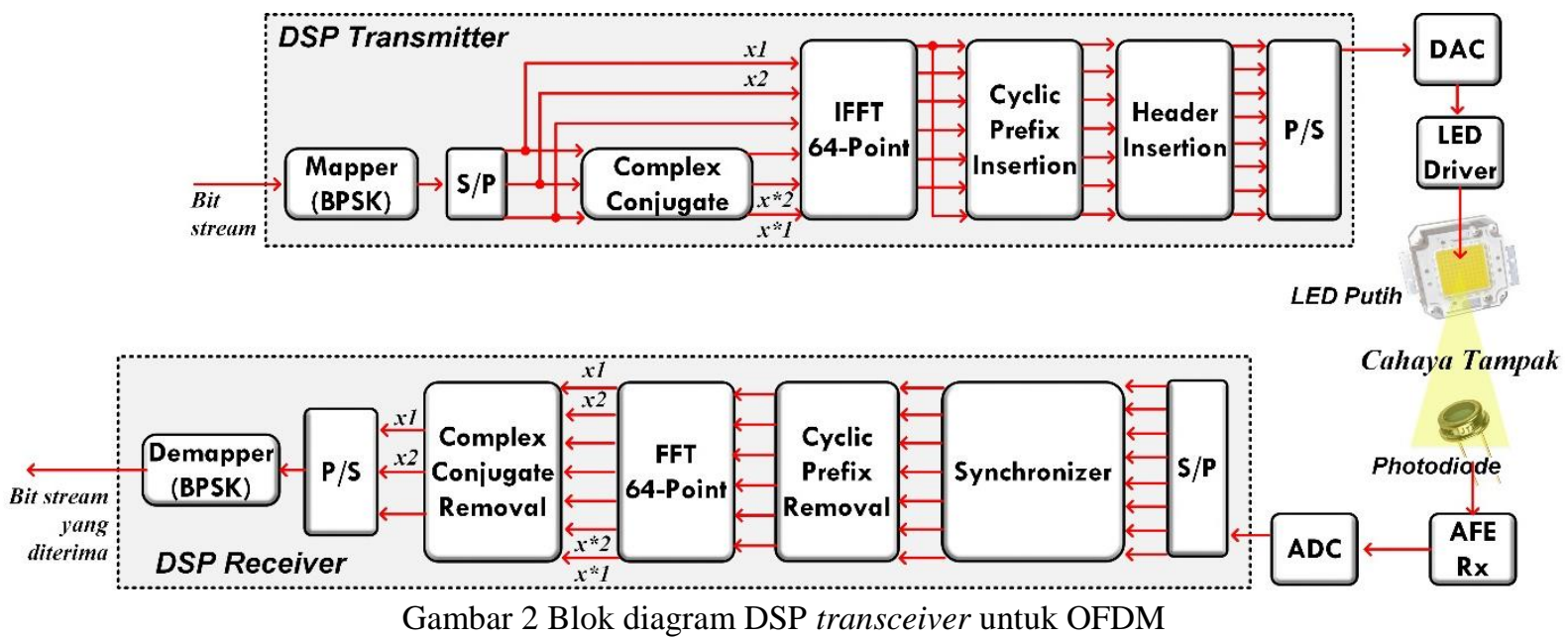

Desain blok DSP transceiver yang telah dirancang, selanjutnya akan diuji fungsionalitasnya menggunakan program simulasi Matlab sebelum diaplikasikan pada mikrokontroller.

Aliran bit stream diterima modul mikrokontroler dari komputer melalui UART. Data ini berupa karakter dalam format ASCII 8 bit. Data bit stream dimasukkan ke mapper (modulator) untuk dipetakan kedalam simbolsimbol. Modulator yang digunakan dalam penelitian ini adalah BPSK. Pada mapper BPSK, satu simbol membawa 1 bit data. Format data satu frame simbol dari sinyal OFDM ditunjukkan pada diagram pada Gambar 3. BPSK membawa 32-bit atau 4 karakter ASCII 8 per framenya (satu periode sinyal OFDM).

Keluaran dari mapper ini masih berupa data serial sehingga diperlukan serial to parallel (S/P) agar data terkumpul menjadi satu frame. Blok S/P mengumpulkan data 32 simbol setiap satu periode. Sebanyak 32 data simbol dalam satu frame ini dimasukkan pada blok IFFT 64-point.

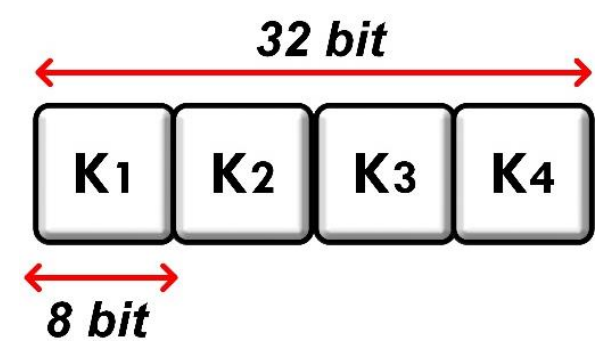

Gambar 3. Data payload untuk modulasi BPSK

Diagram blok OFDM pada Gambar 2 mampu digunakan untuk mapper selain BPSK, yakni QPSK dan QAM. Meskipun keluaran dari mapper BPSK adalah bilangan real, penulis memasukkan blok penghitung complex conjugate dan dihubungkan ke output blok S/P. Fungsi blok complex conjugate adalah untuk 
mengkondisikan agar keluaran dari blok IFFT merupakan bilangan real. Hasil penghitungan complex conjugate ini dihubungkan pada 32 point IFFT lainnya.

Keluaran dari IFFT adalah sinyal OFDM dalam domain waktu yang diumpkan sebagai masukan pada blok cyclic prefix insertion yang merupakan duplikasi sinyal bagian depan (prefix) dan diletakkan dibelakang sinyal (cyclic). Hal ini diperlukan untuk mengatasi inter symbol interference (ISI) antar simbol OFDM. Penambahan cyclic prefix pada sinyal juga tidak akan merubah data yang dibawa sinyal OFDM karena cyclic prefix adalah pengulangan sinyal dalam domain waktu. Cyclic prefix yang dirancang dalam OFDM ini adalah pengulangan 8 titik prefix

Blok selanjutnya adalah penambahan header pada sinyal OFDM dibagian depan yang merupakan suatu sinyal referensi yang telah diketahui pada bagian transmitter dan receiver. Selain itu, digunakan sebagai sinkronisasi pada bagian receiver untuk mendeteksi awal sinyal OFDM sebelum sinyal dimasukkan pada blok FFT di receiver. Panjang header adalah 15 point. Proses sinkronisasi sangat diperlukan untuk menghindari efek ISI. Blok berikutnya adalah Guard interval (GI) pada bagian akhir sinyal yang berfungsi sebagai jeda pemisah antar simbol OFDM.

Selanjutnya deretan angka ini dimasukkan pada blok Digital-to-Analog Converter (DAC). Penulis menggunakan DAC built in yang ada pada modul STM32F4 Discovery Board, dengan kecepatan sampling maksimum 1 Msps. Kecepatan transfer data yang ingin dicapai dalam desain ini adalah 10 kbps dengan menggunakan modulasi BPSK. Jumlah titik sample satu simbol OFDM adalah sebanyak 64 titik. Perhitungan periode 1 simbol OFDM ditunjukkan pada Persamaan (1) dan perhitungan sampling dari DAC ditunjukkan pada persamaan (2). Diketahui kecepatan transfer data dengan modulasi BPSK adalah 10 kbps dan satu frame sinyal membawa 64 bit data. Didapatkan $50 \mu$ s per-sampling

Periode 1 simbol $=\frac{64 \mathrm{bit}}{10 \mathrm{kbps}}=6.4 \mathrm{~ms}$

Periode sampling $D A C=$ $\frac{6.4 \mathrm{~ms}}{128 \text { sampling }}=50 \mu \mathrm{s} / \mathrm{sampling}$
Output dari DAC adalah sinyal analog dengan rentang tegangan $0-3.3 \mathrm{~V}$ dan dimasukkan ke LED driver yang berfungsi untuk mengendalikan level iluminasi LED. LED driver yang digunakan untuk mentransmisikan sinyal OFDM adalah LED driver linier dimana level iluminasi LED akan sebanding dengan besarnya tegangan [14-17].

Sinyal OFDM merambat di ruang bebas menggunakan medium cahaya tampak. Pada sisi receiver, PIN photodiode menangkap cahaya dan membangkitkan sinyal listrik yang proporsional terhadap cahaya yang diterima. Rangkaian AFE receiver bertugas untuk mengkondisikan dan mengkompensasi sinyal yang telah tercampur noise selama merambat pada ruang bebas sehingga dapat diolah dengan benar oleh blok DSP receiver.

Sinyal analog keluaran Mikrokontroller harus dikonversi menjadi digital kembali oleh Analog-to-Digital Converter (ADC). Pengaturan kecepatan sampling ADC ditunjukkan pada Persamaan (3).

ADC Periode sampling $=$ DAC periode sampling

Blok DSP pada receiver yang pertama yaitu blok S/P. Blok berikutnya adalah header detector untuk proses sinkronikasi time base antara transmitter dan receiver. Blok ini berfungsi untuk mendeteksi bagian awal dari sinyal OFDM. Suatu sinyal referensi telah ditambahkan oleh transmitter pada setiap frame sinyal OFDM untuk menandai bagian awalnya. Sinyal referensi yang ditambahkan oleh transmitter ini telah diketahui oleh receiver. Metode pendeteksian header ini menggunakan teknik korelasi silang (cross correlation) antara sinyal referensi yang telah disimpan dalam memori mikrokontroller terhadap sinyal OFDM yang telah di-sampling.

Selanjutnya Hasil operasi korelasi silang akan menghasilkan koefisien korelasi yang bernilai maksimum apabila sinyal referensi yang disimpan oleh receiver bertemu dan berhimpit dengan sinyal referensi yang ada di dalam sinyal frame OFDM. Dengan demikian, time offset dapat ditentukan dan bagian awal sinyal dapat diketahui. Apabila header telah terdeteksi, maka header selanjutnya dibuang dan dimasukkan pada cyclic prefix remover.

Blok Cyclic prefix remover bertugas untuk menghilangkan cyclic prefix yang telah 
ditambahkan oleh transmitter. Cyclic prefix bertugas untuk mengkompensasi adanya error time offset yang berpotensi menyebabkan terjadinya ISI.

Blok DSP berikutnya adalah modul FFT 64-point. Sinyal informasi yang berada di dalam domain waktu ini harus dikembalikan ke bentuk semula yaitu dalam domain frekuensi. FFT bertugas untu mentransformasikan sinyal dalam domain waktu ke dalam domain frekuensi. Namun output dari sinyal informasi yang valid hanyalah 32 point pertama saja karena 32 point sisanya merupakan hasil pencerminan dari 32 point pertama. Maka dari itu, data simbol 32 point dalam bentuk complex conjugate ini dihilangkan oleh blok complex conjugate remover karena tidak diperlukan.

Proses selanjutnya adalah rangkaian bilangan output dari complex conjugate remover dimasukkan pada blok $\mathrm{P} / \mathrm{S}$ sehingga demodulator dapat memproses rangkaian bilangan ini satu per satu atau secara serial. Simbol-simbol yang telah diterima ini harus dikembalikan ke dalam data biner oleh demodulator dalam hal ini adalah BPSK. Metode yang digunakan pada proses demodulasi ini adalah hard decision dimana simbol diterjemahkan ke dalam data biner berdasarkan jarak terdekat dengan titik-titik referensi dalam diagram konstelasi.

Spesifikasi AFE transmitter dan AFE receiver ditampilkan pada Tabel 1 [7].

Tabel 1. Spesifikasi AFE transceiver

\begin{tabular}{|c|c|}
\hline Parameter & Nilai \\
\hline Tegangan input LED driver linier & 0 s.d. $3,3 \mathrm{~V}$ \\
\hline Bandwidth maksimum rangkaian & $50 \mathrm{kHz}$ \\
\hline Daya LED & $9 \mathrm{~W}$ \\
\hline Tegangan kerja LED & 10 s.d $14 \mathrm{~V}$ \\
\hline Warna LED & Putih \\
\hline Respon spektrum Photodiode & 400 s.d. $1000 \mathrm{~nm}$ \\
\hline Photodiode & $\begin{array}{l}\text { PIN Photodiode } \\
\text { SP8-ML }\end{array}$ \\
\hline $\begin{array}{l}\text { Tegangan output rangkaian AFE } \\
\text { receiver }\end{array}$ & 0 s.d. $3,3 \mathrm{~V}$ \\
\hline
\end{tabular}

\section{HASIL DAN ANALISA}

Gambar 4 merupakan hasil simulasi Matlab dengan tiga nilai SNR yang berbeda dimana model kanal yang digunakan adalah Additive white Gaussian noise (AWGN) [18]. Berdasarkan hasil simulasi dapat disimpulkan bahwa semakin rendah SNR, maka titik-titik konstelasi semakin tersebar satu sama lain sehingga berpotensi besar untuk terjadinya error pada data yang terima.

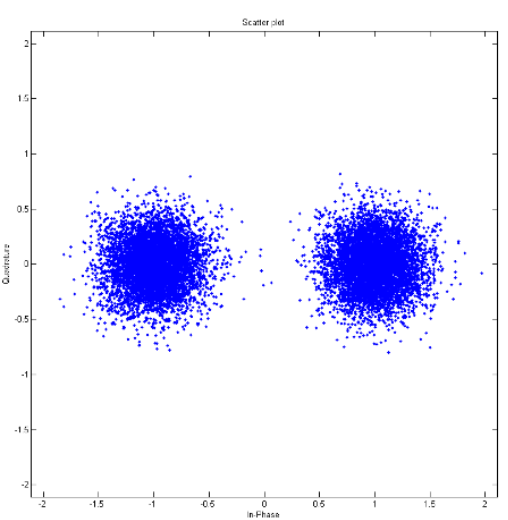

(a)

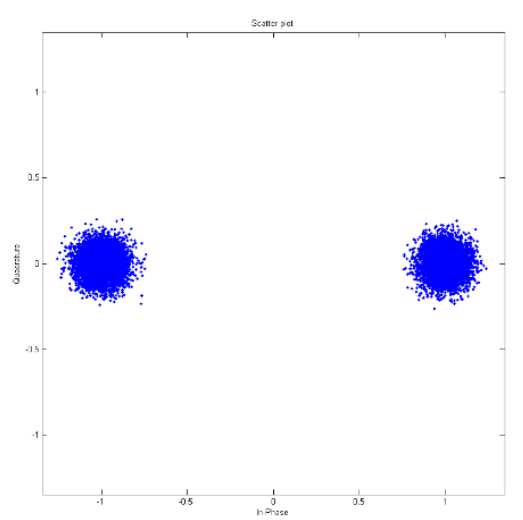

(b)

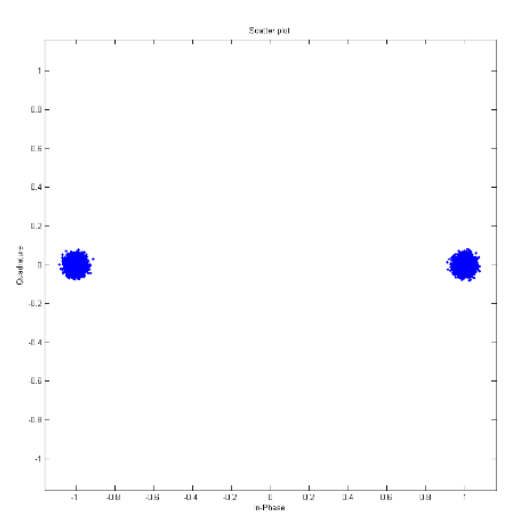

(c)

Gambar 4. Hasil simulasi yang menunjukkan diagram konstelasi data pada output DSP receiver dengan mapper BSPK untuk: (a) SNR = 10; (b) SNR = 20; (c) SNR = 30

Data keluaran dari FFT yang berupa simbol-simbol, selanjutnya dimasukkan pada demodulator (demapper). Keluaran dari demapper BPSK adalah data biner. Data ini dibandingkan dengan data yang dikirimkan oleh transmitter sehingga error dapat dihitung.

Setelah proses integrasi DSP dan AFE transceiver dilakukan, langkah selanjutnya adalah mendemonstrasikan pengiriman sinyal OFDM melalui kanal cahaya tampak. Gambar 5 merupakan setup eksperimen yang dilakukan yang terdiri atas VLC transmitter (Tx Module) dan VLC receiver, osiloskop ( $R x$ module), dan dua buah komputer yakni $R x$ PC dan $T x$ PC.

Sinyal satu simbol OFDM dalam domain waktu ditunjukkan pada Gambar 6 . 
Satu simbol sinyal OFDM terdiri dari header, payload, dan guard interval. Sinyal bagian bawah (warna biru) adalah sinyal input pada transmitter, sedangkan sinyal bagian atas (warna kuning) adalah sinyal output pada receiver. Satu simbol sinyal OFDM memiliki durasi 4,75 ms. Jumlah bit payload data untuk BPSK adalah 64 bit, Perhitungan kecepatan data transfer yang diperoleh untuk BPSK ditunjukkan pada Persamaan (4) dan didapatkan 13,4 kbps.

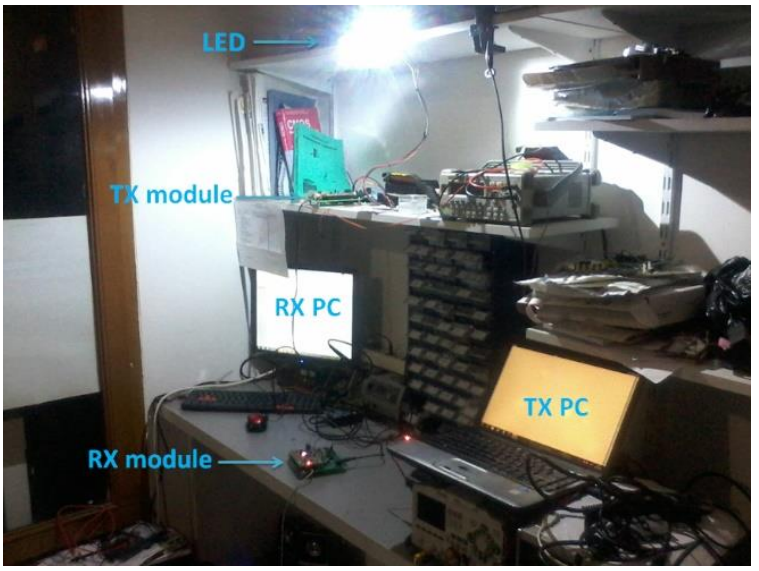

Gambar 5. Skenario pengujian sistem VLC

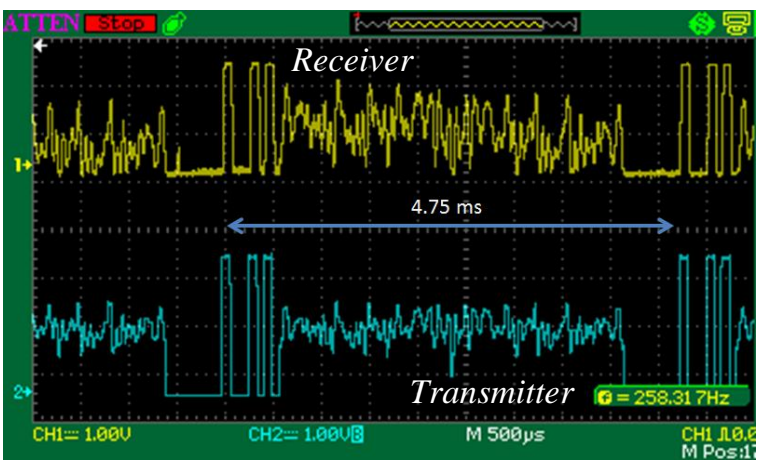

Gambar 6. Hasil tangkapan osiloskop dari sinyal satu simbol OFDM

Tabel 2 merupakan perbandingan kecepatan transfer data sistem VLC dengan modulasi OFDM-BPSK dengan modulasi lainnya pada skenario dan hardware yang sama. Laju data dari OFDM dengan mapper BPSK lebih cepat daripada 1-PWM maupun 2-PWM.

Laju data $(B P S K)=4.75 \mathrm{~ms} \times 64$

Tabel 2. Perbandingan laju data sistem VLC

\begin{tabular}{lll}
\hline \multicolumn{1}{c}{ Referensi } & Jenis modulasi & \multicolumn{1}{c}{ Laju data } \\
\hline$[5],[19]$ & 1-PWM & $3,3 \mathrm{kbps}$ \\
{$[6]$} & 2-PWM & $6,2 \mathrm{kbps}$ \\
Penelitian ini & OFDM-BPSK & $13,4 \mathrm{kbps}$ \\
\hline
\end{tabular}

Pengujian selanjutnya adalah mengukur nilai BER pada sistem VLC terhadap jarak kanal optic dan pengubahan sudut orientasi penerimaan. BER merupakan perbandingan jumlah data error yang diterima oleh rangkaian AFE receiver terhadap keseluruhan data yang dikirim oleh transmitter. Adapun metode pengukuran BER mengacu pada penelitian sebelumnya [19].

Skenario pengujian pertama adalah pengukuran BER terhadap jarak LEDPhotodiode. Dalam skenario ini, transmisi data dari komputer pengirim (Tx PC) ke komputer penerima ( $R x$ PC) dilakukan untuk beberapa jarak yang berbeda yaitu sekitar 30 s.d. $150 \mathrm{~cm}$. Data dalam bentuk teks sebanyak $10 \mathrm{~kb}$ ditransfer dari $T x$ PC ke $R x$ PC melalui medium cahaya tampak. Sudut penerimaan Photodiode terhadap LED dibuat tetap yaitu 0 derajat dalam konfigurasi Line-of-Sight (LoS).

Hasil pengukuran BER untuk beberapa jarak LED-Photodiode ditunjukkan pada Gambar 7. Skenario pengujian sama seperti [5], [6]. Nilai BER pada sistem VLC dengan modulasi BPSK lebih besar dibandingkan dengan modulasi 1-PWM dan 2-PWM.

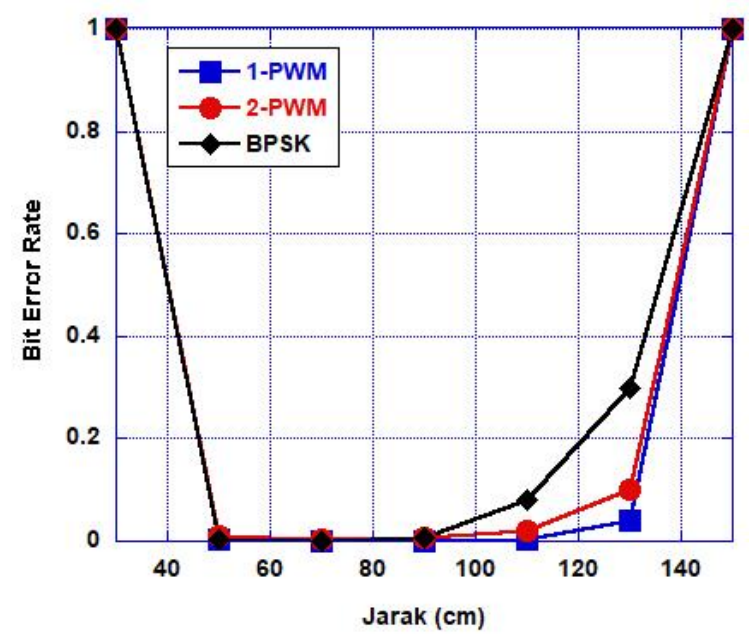

Gambar 7. BER vs jarak LED-Photodiode dengan setting gain A pada modulasi BPSK, 1-PWM dan 2PWM

Untuk jarak yang terlalu dekat yaitu $<50 \mathrm{~cm}$, nilai BER terlalu besar karena sinyal mengalami saturasi akibat intensitas cahaya yang diterima terlalu kuat. Sebaliknya apabila jarak lebih dari $90 \mathrm{~cm}$, maka nilai BER juga besar karena intensitas cahaya yang diterima Photodiode terlalu lemah [20]. Sehingga sistem VLC ini efektif digunakan dalam jarak antara 
50 s.d $90 \mathrm{~cm}$. Dari grafik dapat diamati bahwa meskipun laju data modulasi BPSK lebih cepat dibandingkan 1-PWM dan 2-PWM, nilai BER relatif membesar terutama pada jarak kanal optik diatas $90 \mathrm{~cm}$.

Selanjutnya, dilakukan pengukuran BER dengan setting gain yang lebih rendah dari pada setting gain A agar sinyal yang diterima receiver pada jarak dekat (dibawah $50 \mathrm{~cm}$ ) tidak mengalami saturasi. Blok Preamplifier pada AFE receiver dalam setting gain $B$ dibuat 1x. Hasil pengujian ditunjukkan pada Gambar 8. Dengan setting gain B, maka rentang jarak efektif untuk komunikasi VLC menjadi 20 s.d. $50 \mathrm{~cm}$

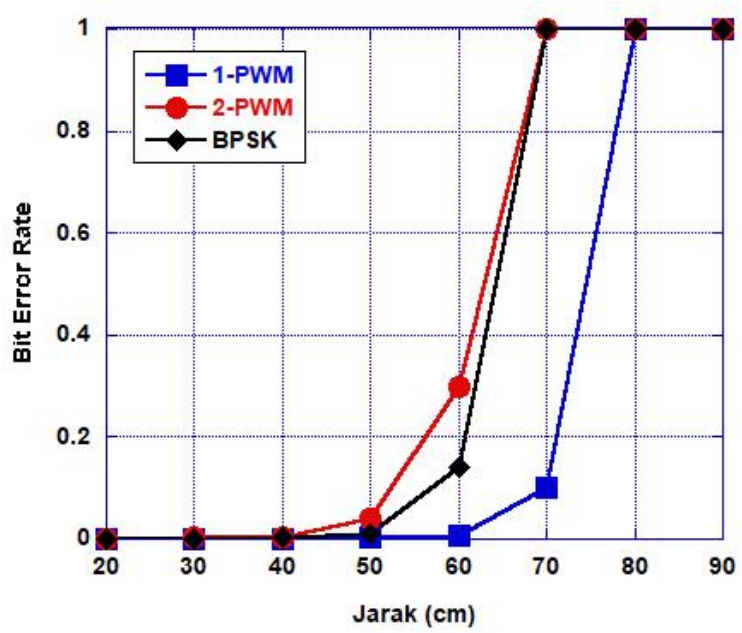

Gambar 8 BER vs jarak LED-Photodiode dengan setting gain B pada modulasi BPSK, 1-PWM dan 2PWM

Dengan mengurangi gain pada Preamplifier, maka nilai BER modulasi BSPK lebih baik dari pada 2-PWM. Secara keseluruhan komunikasi VLC tetap dapat dilakukan dengan baik tidak seperti pada setting gain A. Rentang jarak mobilitas sistem VLC dengan modulasi BSPK berkisar $40 \mathrm{~cm}$.

Skenario pengujian kedua adalah pengukuran BER terhadap sudut penerimaan Photodiode. Pada skenario ini, pengaturan gain B digunakan sebagai parameter. Kemudian jarak kanal optik dibuat tetap namun sudut penerimaan sebagai variabel yakni diatur dalam rentang antara 0 s.d. 50 derajat. Hasil pengukuran BER ditunjukkan pada Gambar 9. Sama halnya dengan skenario pertama, penulis membandingkan modulasi BPSK terhadap 1PWM dan 2-PWM.

Ketiga jenis modulasi yang digunakan menunjukkan tren hasil yang sama yaitu semakin lebar sudut penerimaan Photodiode terhadap LED maka nilai BER semakin besar. Berdasarkan grafik pengukuran disimpulkan bahwa sudut penerimaan efektif dari Photodiode adalah 0 s.d. 30 derajat.

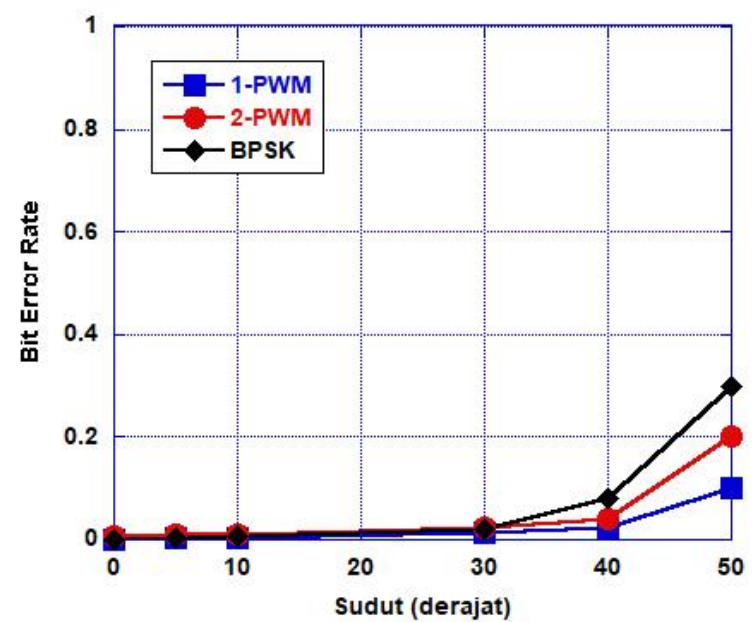

Gambar 9. BER vs sudut penerimaan dengan setting gain B pada modulasi BPSK, 1-PWM dan 2-PWM

Gambar 10 merupakan hasil plot diagram konstelasi OFDM-BPSK yang diproses secara real-time. Plot ditampilkan pada Rx PC melalui GUI yang dibuat menggunakan DELPHI 7.0. Sistem VLC diujikan pada jarak yang berbeda-beda. Berdasarkan hasil plot konstelasi dapat disimpulkan bahwa semakin jauh jarak optik, maka nilai SNR \& Error Vector Magnitude (EVM) semakin rendah sehingga titik-titik konstelasi semakin tersebar atau potensi error data diterima semakin besar. 


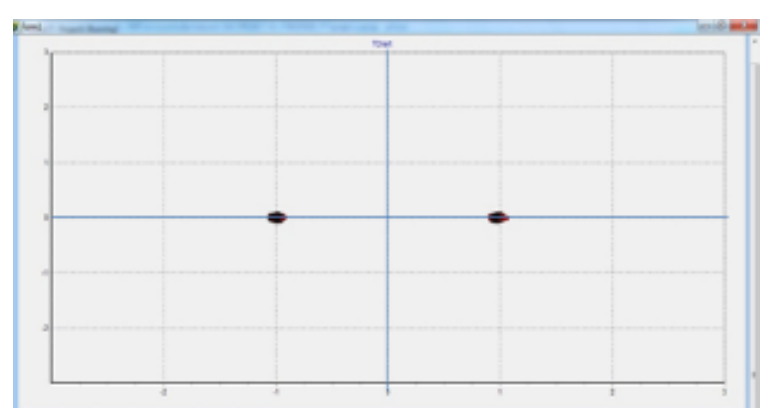

(a)

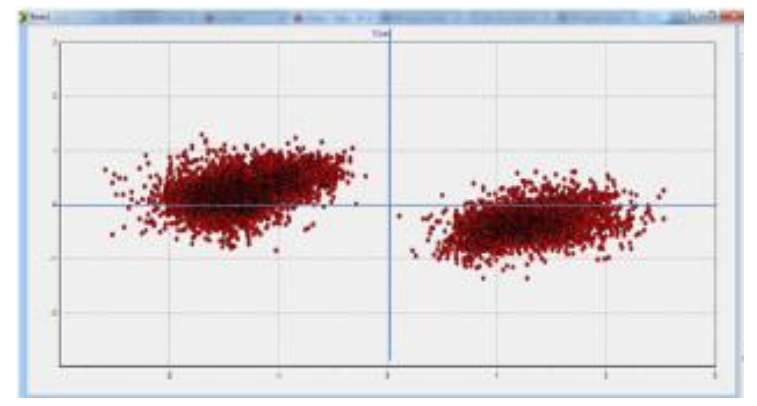

(c)

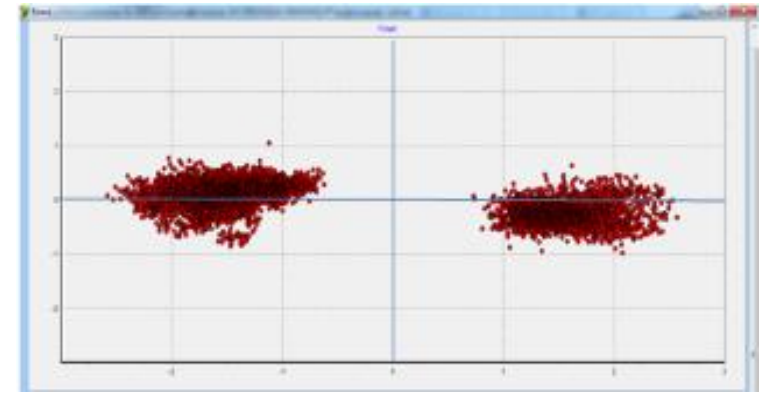

(b)

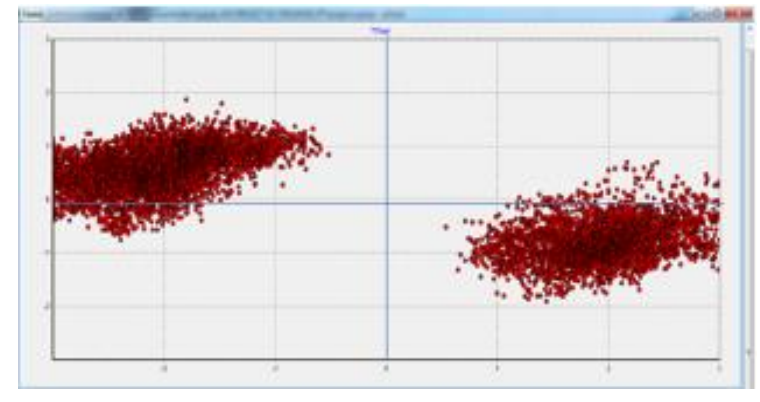

(d)

Gambar 10. Diagram konstelasi modulasi BPSK untuk jarak: (a) $50 \mathrm{~cm}$, (b) $75 \mathrm{~cm}$, (c) $100 \mathrm{~cm}$, dan (d) $130 \mathrm{~cm}$

\section{KESIMPULAN DAN SARAN}

Penelitian ini mengimplementasikan teknik OFDM dengan mapper BPSK untuk sistem VLC Sistem komunikasi data nirkabel berbasis cahaya tampak secara real-time telah berhasil didemonstrasikan dimana kecepatan transfer data OFDM-BPSK adalah 13,4 kbps, atau kurang lebih dua kali lipatdari modulasi 2PWM dan empat kali lipat dari 1-PWM. Hasil pengukuran menunjukkan bahwa nilai BER pada modulasi BPSK cenderung lebih besar daripada modulasi 1-PWM dan 2-PWM meskipun setting gain diubah-ubah.

Keterbatasan kecepatan transfer disebabkan oleh komponen elektronik pada AFE yang memiliki bandwidth rendah dan keterbatasan dalam pemrosesan digital pada mikrokontroller.

Untuk meningkatkan laju data maka disarankan untuk 1) menggunakan komponen AFE dengan spesifikasi high-end, 2) diperlukan teknik modulasi yang membawa lebih banyak dari dua bit (misalnya QPSK, QAM-16, QAM64 atau teknik lain), dan 3) pemilihan prosesor DSP yang lebih cepat yang dalam hal ini, FPGA dapat menggantikan peran generic microcontroller.

Pada penelitian lanjutan, penulis akan memfokuskan untuk menambahkan kanal untuk uplink dengan medium inframerah dan meninjau pengaruh rangkaian filter pada modulasi BPSK dibandingkan dengan modulasi 1-PWM dan 2-PWM.

\section{UCAPAN TERIMAKASIH}

Penelitian ini dibiayai oleh dana Hibah Penelitian dari KEMRISTEK-DIKTI melalui skema Kerjasama Luar Negeri (KLN) kolaborasi dengan Pukyong National University-Korea Selatan, judul proyek penelitian "Machine to machine communication (M2M) based on visible light communication (VLC)" (No. Kontrak: 009/SP2H/LT/DRPM/IV/2017).

\section{REFERENCES}

[1] T. Adiono, S. Fuada, and S. Harimurti, "Bandwidth Budget Analysis for Visible Light Communication Systems utilizing Commercially Available Components," Proc. of the $10^{\text {th }}$ Int. Conf. on Electrical and Electronics Engineering (ELECO), pp. 13751380, December 2017.

[2] S. Fuada and T. Adiono, "Visible Light Communication Kits for Educations," J. of Education and Training, Vol. 5(2), pp. 39-49, May 2018. DOI: 10.5296/jet.v5i2.12578.

[3] A. Burton, H.L. Minh, N. Aslam, and T.D. Nguyen, "LED based lighting and 
communications: An emerging technology for a greener more sustainable future," $E A I$ Endorsed Transactions on Energy Web, Vo. 4(13), pp. 1-6, 2017.

[4] D. Karunatilaka, F. Zafar, V. Kalavally, and R. Parthiban, "LED based Indoor Visible Light Communications: State of the Art," IEEE Communication Survey \& Tutorials, Vol. 17(3), pp. 1649-1678, 2015.

[5] T. Adiono, S. Fuada, and A. Pradana, "Desain dan Realisasi Sistem Komunikasi Cahaya Tampak untuk Streaming Teks berbasis PWM," J. Setrum, Vol. 6(2), pp. 270-279, Desember 2017.

[6] T. Adiono, A. Pradana, and S. Fuada "Rancang Bangun Sistem Komunikasi Cahaya Tampak dengan Modulasi 2-PWM berbasis Mikrokontroller," Jurnal SISFO, 2018.

[7] A. Pradana, "Rancang bangun layer fisik komunikasi cahaya tampak berbasis DCOFDM dan PWM," M.T. thesis, Dept. Elect. Eng., School of Electrical Engineering and Informatics, Institut Teknologi Bandung, Bandung, Indonesia, 2016.

[8] T. Adiono, A. Pradana, and S. Fuada, "A Low-complexity of VLC System using BPSK," Int. J. of Recent Contributions from Engineering, Science and IT (iJES), Vol. 6(1), pp. 99-106, 2018.

[9] D. Astharini, A. Mayola, O.N. Samijayani, and A. Syahriar, "Analisa Kinerja Teknik Modulasi Digital pada Kanal Optik Nirkabel," J. Elektronika dan Telekomunikasi (JET), Vol. 17(1), pp. 7-12, August 2017.

[10] H. Malik, D.R. Rotake, and M. Mahajan, "Design and Implementation of BPSK Modulator and Demodulator using VHDL," IOSR J. of Electronics and Communication Engineering, Vol. 9(3), pp. 98-105, 2014.

[11] M. Sonmez and A. Akbal, "FPGA Based, Low Cost Modulators of BPSK and BFSK, Design and Comparison of Bit Error Rate over AWGN Channel," GU J Sci, Vol. 26(2), pp. 207-213, 2013.

[12] D.S. Suresh, R. Sekar, S. Tejaswini, and B.M. Ankitha, "Realization of Digital Modulation Techniques using TMS320C6748," Proc. of Int. Conf. on Power, Control, Signals, and Instrumentation Engineering (ICPCSI), pp. 1576-1580, 2017.

[13] T. Adiono, S. Fuada, and A. Pradana, "A Circuit for Robust Visible Light Communication Systems in Indoor Environment," Proc. of the Int. Conf. on Information Technology and Electrical Engineering (ICITEE), July 2018.

[14] S. Fuada, T. Adiono, A. P. Putra, and Y. Aska, "A Low-cost Analog Front-End (AFE)
Transmitter Designs for OFDM Visible Light Communications," Proc. of the IEEE Int. Symposium on Electronics and Smart Devices (ISESD), pp. 371-375, October 2016. DOI: 10.1109/ISESD.2016.7886750.

[15] S. Fuada, T. Adiono, A.P. Putra, Y. Aska, "LED Driver Design for Indoor Lighting and Low-rate Data Transmission Purpose, OptikInt. J. for Light and Electron Optics, Vol. 156, pp. 847-856, 2018, DOI: https://doi.org/10.1016/j.ijleo.2017.11.180.

[16] S. Fuada, "Design and Implementation of Analog Front-End Transceiver Module for Visible Light Communication System," M.T. thesis, Dept. Elect. Eng., School of Electrical Engineering and Informatics, Institut Teknologi Bandung, Bandung, Indonesia, 2017.

[17] T. Adiono and S. Fuada, "Desain dan Implementasi LED Driver Linier untuk Aplikasi Visible Light Communication," Unpublished.

[18] T. Adiono, Y. Aska, S. Fuada, and A.A. Purwita, "Design of an OFDM System for VLC with a Viterbi Decoder," IEIE Transaction on Smart Processing and Computing (SPC), Vol. 6(6), pp. 455-465, December 2017.2 DOI: https://doi.org/10.5573/IEIESPC.2017.6.6.45 5.

[19] A. Pradana, S. Fuada, and T. Adiono, "Desain dan Implementasi Sistem Visible Light Communication berbasis Pulse Width Modulation," Majalah Ilmiah Teknologi Elektro, Vol. 17(2), pp. 237-243, 2018.

[20] S. Fuada, A.P. Putra, and T. Adiono, "Analysis of Received Power Characteristics of Commercial Photodiodes in Indoor LoS Channel Visible Light Communication," Int. J. of Advanced Computer Science and Applications (IJACSA), Vol. 8(7), pp. 164172, July 2017. DOI: 10.14569/IJACSA.2017.080722. 